\title{
Regressão da fibrose hepática
}

\author{
Regression of hepatic fibrosis
}

\author{
Zilton A. Andrade ${ }^{1}$
}

\begin{abstract}
RESUMO
Durante muito tempo, se acreditou que a fibrose hepática extensa e de longa duração fosse um processo irreversível. As investigações sobre o comportamento da fibrose hepática, nas formas avançadas da esquistossomose, vieram abalar este conceito e hoje em dia está se estabelecendo a noção de que qualquer fibrose é reversível, inclusive aquela associada à cirrose hepática. O problema é identificar sua causa e removê-la. Embora, a fibrose hepática tenha per se pouca significação fisiopatológica, sua gravidade está relacionada com as alterações vasculares que ela encerra. O que dá ao assunto primordial importância são os indícios até aqui obtidos de que, a regressão da fibrose costuma se acompanhar de uma remodelação das alterações vasculares no seu interior. Mas, há peculiaridades relativas ao tipo anatômico e ao papel fisiológico que certas fibroses exibem, e tais peculiaridades podem interferir com o processo regressivo da mesma, o que pode significar que por vezes a fibrose pode se tornar permanente. Esses assuntos, alguns deles controversos, são aqui apresentados e discutidos.
\end{abstract}

Palavras-chaves: Fibrose hepática. Esquistossomose. Cirrose hepática. Capillaria hepatica.

\begin{abstract}
Extensive and persistent hepatic fibrosis has for a long time been considered irreversible. However, recent studies on the behavior of hepatic fibrosis, especially those related to evolution and involution of advanced schistosomiasis in man, have challenged this concept, and nowadays it is becoming clear that any type of fibrosis is reversible, including that associated with hepatic cirrhosis. The problem consists in identifying and eliminating its cause. Although fibrosis in the liver has little functional significance by itself, its severity derives from associated vascular changes. However, new data on fibrosis regression indicate that disappearance of fibrosis is usually accompanied by remodeling of vascular changes. But, there are peculiarities related to the anatomic type of fibrosis and to its functional significance, which suggest that sometimes fibrosis may indeed be irreversible. These aspects, some of which in need of further studies, are presented and discussed herein.
\end{abstract}

Key-words: Hepatic fibrosis. Schistosomiasis. Hepatic cirrhosis. Capillaria hepatica.

\section{GENERALIDADES}

Os conhecimentos sobre o tecido conjuntivo têm progredido muito nos anos recentes, especialmente no que diz respeito à composição e potencialidades da sua matriz extracelular. 0 tecido que preenche os espaços entre as células, conduzindo os vasos sanguíneos e linfáticos, tem funções óbvias de sustentação e de integração, mas a sua importância vai mais além. Os seus componentes incluem moléculas que são fundamentais para a ancoragem, estimulação e movimentação das células no seu interior e para as interações célula-matriz e célula-célula, pois na matriz extracelular se encontram fatores de crescimento, hormônios, ligandos e moléculas de adesão ${ }^{11}$. Na sua porção não-fibrilar predomina um material amorfo, gelatinóide, constituído predominantemente por glicose-aminoglicanos (ácido hialurônico) e proteoglicanos, que são moléculas sulfatadas que retêm água, e no seu interior circula o líquido intersticial que tem papel crucial na integração de todo o organismo vivo. No interior deste líquido circulam os nutrientes e 0 oxigênio, e nele são eliminados os produtos de desgaste resultante do catabolismo celular. 0 equilíbrio de todo o tecido conjuntivo é dinâmico. A todo o momento ele está sendo alterado e re-modelado.

\footnotetext{
1. Laboratório de Patologia Experimental do Centro de Pesquisas Gonçalo Moniz da Fundação Oswaldo Cruz, Salvador, BA. Auxílio Financeiro: PRONEX - FAPESB

Endereço para correspondência: Prof. Zilton A Andradre. Laboratório de Patologia Experimental/CPqGM/FIOCRUZ. Rua Valdemar Falcão 121, Brotas, 40295-001 Salvador, BA.

Tel: 5571 3356-4320 Ext: 602

e-mail: zilton@cpqgm.fiocruz.br

Recebido para publicação em 03/02/2005

Aceito em 14/8/2005
} 
Há forças que operam para aumentar a quantidade da matriz extracelular (fibrogênese) e outras que operam em sentido contrário quando há excesso da mesma (fibrólise).

Quando, por circunstâncias geradas por fatores inflamatórios, degenerativos ou neoplásicos, os estímulos para a fibrogênese superam aqueles da fibrólise, o tecido fibroso se acumula em excesso, constituindo a fibrose. Mas, quando as causas que provocaram estas alterações são eliminadas, ocorre o processo inverso, e o excesso de tecido fibroso é removido, quando os fatores que conduzem à fibrólise passam a predominar. Neste processo, a idade da fibrose é um fator crucial. 0 colágeno, uma esclero-proteína, que dá as principais características à matriz extracelular e à fibrose, quando recém sintetizado pelas células do tecido conjuntivo e depositado extracelularmente pode ser facilmente degradado, uma vez cessado o estímulo fibrogênico. Todavia, a permanência das fibras na matriz, motivada pela atuação continuada da causa, possibilita modificações químicas nas moléculas do colágeno (formação de pontes de lisina, crosslinkings), resultando no seu amadurecimento e conseqüente maior resistência à degradaçãa ${ }^{45}$. Observando os processos que levam à fibrose e à sua remoção, podemos tirar uma conclusão, na verdade limitada por sua natureza teleológica, mas de bom sentido didático, de que tudo sugere que a natureza tem interesse em manter uma relação estroma-parênquima dentro de certos limites, pois só assim as trocas vitais podem se processar satisfatoriamente. Desta maneira, podemos dizer que, qualquer fibrose é reversível, uma vez sua causa sendo afastada. Nas fibroses recentes, a remoção é rápida. Nas mais antigas a remoção pode ser muito mais demorada.

A noção de que a fibrose pode ser degradada e eliminada é bem antiga. A natureza nos dá exemplos tanto no terreno da fisiologia, como no da patologia ${ }^{40}$. No momento do parto ocorre nítida degradação da matriz do colo uterino, permitindo o seu amolecimento; na embriogênese e morfogênese há muitos exemplos de degradação e reabsorção do tecido conjuntivo. Os reumatologistas sabem há muito tempo que, entre os surtos de artrite, a fibrose pode diminuir ou desaparecer nas articulações, o que também se observa nas doenças periodontais. No processo de angiogênese, bem como no crescimento infiltrativo das neoplasias e suas metástases a ocorrência de prévia degradação da matriz extracelular é reconhecida de longa data. Mas, por muito tempo prevaleceu a impressão de que a remoção do tecido fibroso acontecia apenas nestes processos limitados, em pequenas proporções, mas que, quando a fibrose resultava de uma doença e envolvia uma parte substancial de um órgão, ela era irreversível. Este conceito ou crença começou a ser abalado por várias pesquisas feitas nos quatro cantos do mundo a partir das últimas décadas do século passado. Neste particular, os estudos sobre a fibrose hepática associada com a esquistossomose tiveram participação decisiva. A esquistossomose foi a primeira doença humana em que se demonstrou que uma extensa fibrose hepática podia regredir, tanto morfológica, como funcionalmente. Muitos destes estudos foram feitos no Brasil, tanto na área experimental, como na clínica.

\section{FIBROSE HEPÁTICA}

A fibrose é o resultado mais temível das doenças crônicas que afetam o fígado. Os estudos mais recentes têm trazido um aporte impressionante de dados básicos sobre diversos fatores estimulantes da fibrose ${ }^{22} 2336$, bem como sobre os elementos celulares envolvidos na fibrogênese $e^{1623}$, e as possibilidades de regressão da fibrose após a remoção da sua causa (fibrólise) ${ }^{1}$. 0 fígado tem vários elementos celulares capazes de sintetizar e depositar os componentes da matriz extracelular (fibroblastos, miofibroblastos e até os próprios hepatócitos). Todavia, vários estudos têm demonstrado que a célula-chave na produção da fibrose no fígado é a célula estrelada de Ito, situada no espaço de Disse ${ }^{2425}$. Esta é uma célula armazenadora de gordura e vitamina A que, sob a ação de citocinas fibrogênicas, (TGF- $\beta$, TNF- $\alpha$, PDGF e outras), se diferencia em miofibroblasto e fibroblasto, se engajando na ativa síntese dos elementos da matriz (colágenos, elastina, proteoglicanos e proteínas de constituição).

As citocinas fibrogênicas, como o TGF- $\beta$, PDGF, TNF- $\alpha$ etc, são produzidas por células inflamatórias (macrófagos, linfócitos CD4), hepatócitos e células de Kupffer, em seguida a estímulos variados ${ }^{41}$. Embora alguns estudos tenham tentado utilizar marcadores externos da fibrose, com aparente sucesso nos casos das dosagens séricas do telopeptídeo do pro-colágeno I, do hialuran, do TGF- $\beta$ ou da excreção da hidroxiprolina urinária, o presente consenso é de que ainda não estão disponíveis marcadores confiáveis de fibrose hepática ${ }^{23} 43$.

Um outro problema crucial diz respeito ao tratamento da fibrose hepática. Não há ainda uma droga eficaz, embora muitas tenham sido ensaiadas. Pode-se tentar inibir fatores fibrogênicos, mas até o momento os melhores resultados são conseguidos quando a causa da fibrose é removida ${ }^{10}$. A fibrose tem causa multifatorial, muitas delas ainda desconhecidas. Estas precisam ser atacadas, pois uma droga curativa para uma determinada etiologia, possivelmente não será eficaz para outra. Neste contexto há ainda o problema do modelo experimental adequado para se fazer os testes com as drogas ${ }^{253}$.

Finalmente, um outro problema que parece dos mais interessantes diz respeito à participação de mecanismos imunológicos na gênese da fibrose. Embora, a participação do sistema imune seja sempre considerado nos processos fibrosantes hepáticos, como nas hepatites virais, no alcoolismo crônico, na cirrose biliar primária e, particularmente, nas hepatites e colangites auto-imunes, a noção dominante é de que a participação dos fatores imunológicos se faz através de mecanismos mais gerais e importantes, decorrentes da inflamação crônica e/ou das necroses hepatocelulares repetidas ${ }^{47}$. Todavia, os estudos in vitro têm demonstrado, por exemplo, que certos fatores podem estimular as células de Kupffer a liberar citocinas fibrogênicas que induzem as células estreladas de Ito a sintetizar os componentes da matriz extracelular ${ }^{2425}$. Pelo menos dois modelos experimentais revelam que uma fibrose septal, disseminada por todo o fígado, pode surgir na ausência de necrose hepatocelular e inflamação crônica evidentes, provavelmente condicionados por uma base imunológica' ${ }^{12} 213748$. 


\section{A REVERSIBILIDADE DA FIBROSE HEPÁTICA NA ESQUISTOSSOMOSE}

Aspectos clínicoepidemiológicos. Em 1966, Katz \& Brener $^{32}$ re-visitaram uma área endêmica de esquistossomose, isolada no Estado de Minas Gerais, dez anos depois de uma primeira visita, quando eles tinham catalogado os dados de 112 pacientes com as várias formas da infecção. Registraram que dos 91 pacientes com a forma leve da infecção 7 tinham evoluído para a forma grave. Por outro lado, dos 21 portadores da forma hepato-esplênica vistos durante a primeira visita, em 8 deles a esplenomegalia havia regredido. E não constava que eles tivessem recebido qualquer tratamento anti-esquistossomótico! 0 relato desta experiência foi recebido pelos estudiosos do assunto com um misto de surpresa e curiosidade.

Bina $^{13}$, em 1977, fez o tratamento de pacientes em diferentes estágios da infecção esquistossomótica numa área hiperendêmica. Utilizou uma nova droga (Hycanthone), que parecia muito eficaz. Seis anos depois ele fez a avaliação dos resultados. Verificou que, de 115 pacientes tratados, 4 de 11 passaram da forma hepato-esplênica para a forma intestinal (leve) da doença, enquanto todos os outros tratados estacionaram ou melhoraram o seu quadro clínico. Ao mesmo tempo, dos 115 controles não tratados 21 passaram da forma hepato-intestinal para a forma hepato-esplênica e os demais não tiveram a sua forma clínica mudada, embora uns tivessem melhorado e outros piorados.

Este estudo sugeria que o tratamento era curativo e preventivo das formas graves, embora não impedisse os indivíduos de se re-infectarem. Esta verdade foi confirmada após o tratamento em larga escala das populações nordestinas, o que veio a reduzir drasticamente a existência das formas avançadas da esquistossomose entre nós, embora sem igual impacto sobre a presença de esquistossomose-infecçãa ${ }^{4}$.

Os trabalhos clínicos bem controlados se seguiram e consolidaram a noção da possibilidade de reversão ou diminuição da fibrose hepática humana avançada, alguns anos após o tratamento $0^{14303546}$. Quando o tratamento é feito em indivíduos jovens com a forma hepato-esplênica da esquistossomose, a reversibilidade do quadro clínico já pode ser notada seis meses mais tarde ${ }^{19}$.

Os estudos realizados através biópsias cirúrgicas de pacientes, feitas no momento mesmo da esplenectomia, vieram demonstrar a presença de sinais inequívocos de degradação da fibrose periportal, mesmo em indivíduos com esquistossomose antiga e que não receberam tratamento específico ${ }^{18}$. Estes sinais morfológicos de degradação foram os mesmos que já tinham sido observados em material experimental, caracterizados ao microscópio eletrônico especialmente pelos focos de alterações líticas ${ }^{7}$. Como tais focos eram tão freqüentes e aparentemente extensos, houve a suspeita de que eles poderiam ser notados mesmo nas preparações de microscopia de luz. E logo isso foi confirmado. A fibrose portal densa e compacta no comum dos casos de esquistossomose hepato-esplênica, por vezes aparecia com várias áreas de rarefação, onde as fibras colágenas apareciam degradadas, transformadas em pequenos fragmentos de espessura variada, por vezes transformados em grumos ${ }^{8}$.

Com o desaparecimento dos sinais de hipertensão porta (retorno do baço ao seu volume habitual e desaparecimento das varizes de esôfago) nos casos tratados e curados, ficou evidente que, a eliminação da fibrose se acompanha também de uma remodelação das lesões vasculares.

A noção de que as alterações vasculares associadas com a fibrose hepática podem vir a ser moduladas e revertidas com a cura da fibrose, ainda não foi devidamente avaliada em outras condições, como na cirrose hepática, mas é assunto da maior importância atual, a necessitar de estudos futuros.

Aspectos experimentais. Dados sobre a eficácia do tratamento da esquistossomose apareceram nos trabalhos experimentais de Gonnert ${ }^{27}$, Cameron \& Ganguly ${ }^{17}$, e Warren ${ }^{55}$, que mostraram que os granulomas, a hepatite reacional e a fibrose desapareciam do fígado dos camundongos tratados. Mas, logo surgiram estudos demonstrando que tais dados só eram válidos para a esquistossomose recente ( 8 a 10 semanas após a exposição cercariana), pois a fibrose das infecções tardias (16 a 20 semanas) era irreversível ${ }^{15} 37$.

Tendo em conta estes dados, que indicavam a existência de uma esquistossomose reversível (recente) e outra irreversível (tardia), Andrade $\&$ Grimaud $^{6}$ procuraram verificar se tal diferença se devia à presença de diferentes tipos de colágenos, pois havia dados indicativos de que o colágeno de tipo III, predominante nas processos recentes de fibrose, era mais facilmente degradável do que o colágeno de tipo I, que predominava nas fibroses densas e antigas. Verificaram então que, os dois tipos principais de colágeno estavam presentes nos granulomas periovulares da infecção recente, sendo realmente o tipo III mais abundante nas infecções recentes. Entretanto, após o tratamento curativo, os dois isotipos genéticos de colágeno desapareciam ao mesmo tempo. Até nos minúsculos granulomas residuais se podia demonstrar a presença dos dois isotipos. Neste mesmo trabalho, os AA se dedicaram a examinar as alterações ultraestruturais da fibrose em degradação. Observaram que 0 quadro era o mesmo já descrito para outros modelos de degradação do colágeno, como por exemplo, na involução pósparto do útero grávido da rata ${ }^{29}$, na reabsorção do granuloma da carragenina ${ }^{38}$. Em todos estes modelos invariavelmente foram encontradas duas alterações ultraestruturais fundamentais: a fragmentação extracelular do colágeno e a internalização (fagocitose?) de fragmentos do colágeno por fibroblastos e macrófagos.

Ainda com a idéia de verificar por que os granulomas da esquistossomose tardia eram irreversíveis, Andrade \& Grimaud $^{7}$ examinaram mensalmente camundongos tratados na fase crônica ou tardia da infecção (16-20 semanas). Realmente, nos dois primeiros meses pós-tratamento, quando a fibrose já exibia nítidas evidências de degradação nos animais recentemente infectados e tratados, nada acontecia 
aos animais tratados na fase crônica da infecção. Mas, se a observação se estendesse por mais tempo, já no terceiro mês as evidências de involução das lesões podiam ser percebidas, e elas se tornaram nítidas no quarto mês pós-tratamento. Desaparecia tanto a fibrose dos granulomas periovulares, como a fibrose periportal, a qual representa um modelo experimental da fibrose pipestem de Symmers ${ }^{56}$. Assim sendo, ficou claro que a noção da irreversibilidade da fibrose na esquistossomose tardia se baseava em experimentos em que o tempo de observação pós-tratamento deixou de ser suficientemente prolongado.

Sabendo agora que, cerca de 3-4 meses após o tratamento curativo, a fibrose hepática esquistossomótica se degrada lentamente, Andrade \& Grimaud $^{7}$ procuraram saber se o seu aspecto ultra-estrutural diferia daquele conhecido para a degradação aguda. Viu-se na fibrose dos granulomas em regressão aspectos completamente diferentes, caracterizados por dois achados distintos. Em um deles o colágeno, transformado em minúsculos grânulos, se concentrava em focos que apareciam escuros, dissociando os feixes colágenos bem conservados (alteração eletrodensa). 0 outro achado consistia em espaços claros que interrompiam a disposição dos feixes colágenos, sugerindo focos de dissolução de um tecido pré-existente (alteração lítica). Podemos assim dizer, que há dois tipos de degradação do colágeno: um que envolve a fibrose de formação recente, que se processa de maneira relativamente rápida e se caracteriza por dois achados ultra-estruturais: fragmentação extracelular do colágeno e internalização de fragmentos do colágeno (degradação aguda); outro que ocorre lentamente, exibindo quadro ultra-estrutural com alterações focais eletrodensa e lítica. Para os patologistas, estrutura e função têm uma relação indissociável. Se os aspectos morfológicos são diferentes há fortes indícios de que os mecanismos envolvidos sejam também diferentes. Tudo o que se sabe sobre os mecanismos de degradação da fibrose foi estudado em modelos experimentais de degradação aguda. 0 exemplo mais marcante foi a observação do desaparecimento da cauda do girino, em que o colágeno é degradado em horas ou dias, e que permitiu a descoberta da colagenase ${ }^{28}$. Os complexos mecanismos de atuação das metaloproteinases e seus inibidores foram geralmente estudados em modelos como a involução pós-parto do útero da rata, o granuloma por carragenina, a fibrose hepática por tetracloreto de carbono, observada após a retirada da droga e assim por diante ${ }^{39}$.

Mas, quais são os fatores que atuam na degradação da matriz extracelular e que fazem com que uma extensa fibrose hepática de um portador da forma hepato-esplênica da esquistossomose seja reabsorvida 6 meses a 2 anos após a cura da parasitose? Simplesmente não há uma resposta satisfatória no momento.

Para verificar se os fatores clássicos envolvidos na degradação aguda da fibrose estão também presentes na degradação crônica, Gómez cols ${ }^{26}$ estudaram fígados de portadores de esquistossomose que apresentavam fibrose com os sinais microscópicos de degradação crônica e neles pesquisaram a presença de metaloproteinases (MMP-9 e
MMP-2) e de seus inibidores (TIMP-1 e TIMP-2) pela técnica da imunohistoquímica. Enquanto nos granulomas recentes estes fatores estiveram expressos, nos granulomas antigos e na fibrose periportal, eles estiveram ausentes. Assim sendo, os mecanismos envolvidos na degradação aguda da fibrose não parecem participar da degradação crônica ou então sua participação se faz de uma maneira tal, que as técnicas imunohistoquímicas correntes não conseguem detectar.

\section{A REVERSIBILIDADE DA CIRROSE HEPÁTICA}

Aspectos clínicos. Quando se discute a possibilidade de reversibilidade da cirrose hepática deve ficar bem claro o que se está discutindo. Não se deve confundir cirrose com fibrose, pois esta última é apenas um dos componentes da cirrose e ela é reversível, pelo menos parcialmente, quando sua causa é eliminada. 0 que faz a peculiaridade da cirrose é um processo generalizado de regeneração nodular do parênquima, acompanhado de um complexo de alterações vasculares, que inclui fístulas porto-hepáticas e artériovenosas intra-hepáticas, desvios porto-sistêmicos (circulação colateral), capilarização sinusoidal, alterações estas que privam mais ou menos os hepatócitos do contacto com a sua matéria prima, a qual é da região esplâncnica (intestinos) pela circulação porto-mesentérica ${ }^{42}$.

Quando Laennec usou o termo cirrose pela primeira vez em 1819, ele queria então se referir à cor amarelada que o fígado finamente nodular dos alcoólatras crônicos exibia ao ser examinado na mesa de necropsia. Depois o termo foi interpretado como significando um fígado duro, esquirroso, fibrosado. A cirrose é uma condição terminal a que o fígado é levado nas agressões crônicas de variadas etiologias. Como uma condição importante pela sua frequiência houve necessidade de se definir com precisão o que cirrose significa. Depois de muitas idas e vindas, chegou-se a um conceito anatomoclínico, que é o atualmente aceito. 0 conceito clínico é o de uma doença crônica do fígado, de variada etiologia, que cursa com manifestações de insuficiência hepática e hipertensão porta. Já o conceito anatômico prevê a presença de fibrose que envolve todo o fígado, acompanhada da transformação do parênquima em nódulos regenerativos.

o problema é que os dois quadros, o anatômico e o clínico podem estar dissociados. Há indivíduos que apresentam sinais de hipertensão porta e insuficiência hepática de graus variáveis, mas que não têm o quadro anatômico da cirrose. A recíproca também é verdadeira e isto tem dado lugar a mitos e dogmas sobre a reversibilidade da cirrose ${ }^{18}$.

Tem se chamado muito a atenção nos anos recentes que, quando um indivíduo tem um quadro clínico de cirrose causada, digamos, pelo alcoolismo crônico, por hemocromatose, hepatite crônica B ou C, etc, e a sua causa é removida ou atenuada, pode haver o desaparecimento dos sintomas e sinais da cirrose ${ }^{102331}$. Isto significa que a cirrose é clinicamente reversível. Mas, teria o quadro anatômico desaparecido total ou parcialmente? Este é um aspecto de difícil comprovação, pois, por razões éticas, não se vai fazer 
biópsia em indivíduos sadios. Mesmo assim, pode-se suspeitar que a biópsia não seria uma técnica adequada para se excluir a possibilidade de cirrose anatômica em tais casos. 0 exame do fígado inteiro se impõe e isto aparentemente ainda não foi feito de modo satisfatório ${ }^{34}$. Recentemente, Wanless cols ${ }^{54}$ recorreram ao exame de fígados cirróticos explantados. Eles listaram uma série de achados histopatológicos, ao que denominaram de complexo de reparo hepático. 0 complexo incluía: septos fibrosos delicados e perfurados, fibras colágenas espessas e isoladas, delicadas projeções septais peri-portais, restos de espaços porta, veias hepáticas residuais com hepatócitos prolapsados, hepatócitos no interior de espaços porta, nódulos regenerativos minúsculos e veias parenquimatosas aberrantes. No fundamental os nódulos regenerativos se expandiram e os septos fibrosos se afinaram e muitas vezes se romperam tornando-se incompletos e formando esporões projetados para o interior do parênquima. Tal quadro anatômico caracteriza a chamada cirrose septal incompleta ${ }^{49}{ }^{50}$, que Wanless cols sugerem que seria aquele de uma cirrose em regressão.

As dificuldades em se esclarecer o problema da reversibilidade da cirrose hepática com material humano, têm estimulado os estudos com modelos experimentais.

Aspectos experimentais. 0 modelo experimental mais extensamente usado para responder aos problemas da cirrose hepática é o do rato submetido ao tratamento repetido pelo tetracloreto de carbono $\left(\mathrm{Cl}_{4} \mathrm{C}\right)$ ou pela di-metil-nitrosameina $(\mathrm{DMN})^{39}$. Os resultados sobre a reversibilidade da cirrose têm sido observados em vários períodos de tempo após a suspensão da droga. Mas, eles têm sido contraditórios, possivelmente relacionados com o estágio de evolução da cirrose quando da parada da administração da droga. Perez-Tamayo ${ }^{39}$ fez uma excelente revisão do assunto e concluiu muito judiciosamente que: provavelmente há um estágio quando a cirrose do rato é reversível e outro quando ela é irreversível ou pelo menos em que a reversibilidade é muito lenta. Para Quinn \& Hingginson ${ }^{44}$ tudo na cirrose experimental é reversível, exceto os nódulos regenerativos hepatocitários.

Recentemente, Di Vinicius cols ${ }^{20}$ abordaram o problema da reversibilidade da cirrose no rato. 0 objetivo foi o de verificar se os achados observados em material humano e listados como complexo de reparo estavam presentes na cirrose do rato e, caso estivessem, se eles, de fato, indicariam uma cirrose em regressão do seu quadro morfológico. Di Vinicius cols ${ }^{20}$ usaram ratos com cirrose induzida pelo $\mathrm{Cl}_{4} \mathrm{C}$ e comprovada por biópsia hepática ao fim do tratamento. Seguiram estes animais por 9 meses, sacrificando dois por mês, após a suspensão do tratamento. Observaram que os sinais descritos como complexo de reparo de fato podiam ser identificados $\log 0$ alguns meses após ter cessado a administração do $\mathrm{Cl}_{4} \mathrm{C}$, mas eles não foram seguidos pelo desaparecimento da cirrose. Após a suspensão da droga os nódulos regenerativos se expandiram e os septos fibrosos ficaram mais finos e muitas vezes fragmentados, incompletos. Todas estas alterações foram vistas 4 meses após a suspensão da droga, mas não se modificaram significativamente daí por diante. Os finos e longos septos fibrosos presentes, delimitando grandes nódulos, persistiam aos noves meses da observação póstratamento. Eram septos, que em preparações com injeções vasculares de tinta, mostraram-se vascularizados, com vasos que carreavam material diretamente para os sinusóides situados entre as traves hepáticas que formavam os nódulos persistentes. Eram, portanto, septos fisiologicamente ativos. Talvez por isso, estes septos fibrosos e os seus vasos, tenham sido conservados quando, após a suspensão da administração do $\mathrm{Cl}_{4} \mathrm{C}$, houve uma extensa degradação do excesso de tecido fibroso. Isto contribuiu para a persistência do padrão anatômico da cirrose, embora todos os indícios apontem que os distúrbios clínicos tenham desaparecido por completo nos ratos após a suspensão do tratamento $\mathrm{com} \mathrm{Cl}_{4} \mathrm{C}$.

Estas observações sobre a importância da vascularização da fibrose septal e sua relativa irreversibilidade foram ampliadas com os estudos feitos com o modelo da Capillaria hepática no rato, como se verá a seguir.

\section{A CONTRIBUIÇ̃̃O DOS ESTUDOS EXPERIMENTAIS COM O MODELO DA CAPILLARIA HEPÁTICA}

Ratos infectados com o nematódeo Capillaria hepatica invariavelmente desenvolvem uma fibrose hepática septal, fina e disseminada, por volta de 20-30 dias após a infecção ${ }^{21}$. Embora, um pouco mais acentuada, esta fibrose é semelhante à do modelo obtido em ratos através de injeções repetidas de soro de porco ou de sua fração albumina ${ }^{37}$. Ambos os modelos experimentais encerram aspectos bem interessantes para os estudos sobre patogenia, uma vez que neles a fibrose se desenvolve aparentemente sobre uma base imunológica ${ }^{12}{ }^{33}$, sem manifestações evidentes de inflamação crônica ou de necrose hepatocelular repetida ${ }^{2148}$. Todavia, a fibrose septal da capilaríase hepática é aqui agora considerada pelo que ela pode nos ensinar sobre as peculiaridades da reversibilidade da fibrose hepática. Durante o seu ciclo vital as larvas da $C$. hepatica se tornam vermes no interior do fígado do hospedeiro e aí depositam os seus ovos, vindo a morrer algum tempo depois. Nos ratos todos os vermes já estão mortos ao fim do primeiro mês da infecção. A fibrose septal se inicia um pouco antes e se acentua no mês seguinte, se mantendo aparentemente estável até o quarto mês. Mas, a partir daí a fibrose começa a regredir, ficando cada vez mais fina, fragmentada e ondulada. Todavia não desaparece por completo. Após um ano ou um pouco mais, a fibrose septal permanece e as técnicas de injeção da veia porta com tinta da China revelam que os finos septos contêm vasos que se abrem em leque no interior dos sinusóides ${ }^{51}$. Os ovos depositados em lesões fibróticas focais começam a perder sua viabilidade (capacidade de embrionamento) por volta do $4^{\circ}$ mês pós-infecção e se tornam inviáveis a partir do $6^{\circ}$ mês. Portanto, podemos admitir que todos os estímulos parasitários estejam ausentes a partir do $6^{0}$ mês pós-inoculação. 0 que faz com que a fibrose septal persista mesmo assim? A nossa interpretação é de que certos septos fibrosos, formados como uma resposta ou adaptação do fígado aos estímulos inflamatórios, necrotizantes e/ou imunológicos, representem uma via alternativa de irrigação 
dos sinusóides hepáticos e podem passar a ter um significado fisiológico de sustentação vascular, semelhante ao da fibrose de um espaço porta. São portanto permanentes ou irreversíveis, ao contrário de outros tipos de fibrose, como a fibrose portal da esquistossomose, a fibrose focal dos granulomas em torno dos ovos da $C$. hepatica, a fibrose perisinusoidal, as faixas e septos sem vasos fisiologicamente ativos ou avasculares etc.

Estes dados experimentais observados na involução da fibrose septal da capilaríase do rato, junto aqueles vistos na cirrose experimental em regressão, sugeriram estes comentários finais: a cirrose hepática é reversível no seu conceito clínico, mas relativamente irreversível do ponto de vista anatomopatológico, uma vez que os septos fibrosos que conduzem vasos para o interior dos sinusóides tendem a persistir como se fossem estruturas normais, mesmo quando circunscrevendo nodulações do parênquima.

\section{REFERÊNCIAS BIBLIOGRÁFICAS}

1. Andrade ZA. Evolution and Involution of Hepatosplenic Schistosomiasis. Memórias do Instituto Oswaldo Cruz 84 (supl I): 58-75, 1989.

2. Andrade ZA. Contribution to the study of septal fibrosis of the liver. International Journal of Experimental Pathology 72: 553-562, 1991.

3. Andrade ZA. Extracellular matrix degradation in parasitic diseases. Brazilian Journal of Medical and Biological Research 27: 2273-2281, 1996.

4. Andrade ZA. The situation of hepatosplenic schistosomiasis in Brazil today. Memórias do Instituto Oswaldo Cruz 93 (supl 1): 313-316, 1998.

5. Andrade ZA, Cheever AW. Characterization of the murine model of schistosomal hepatic periportal fibrosis ("Pipestem" fibrosis). International Journal of Experimental Pathology 74: 195-202, 1993.

6. Andrade ZA, Grimaud JA. Evolution of schistosomal hepatic lesions in mice after curative chemotherapy. The American Journal of Pathology 124: 59$65,1986$.

7. Andrade ZA, Grimaud JA. Morphology of chronic collagen resorption. (A study on the late stages of schistosomal granuloma involution). American Journal of Pathology. 132: 389-399, 1988.

8. Andrade ZA, Peixoto E, Guerret $\mathrm{S}$, Grimaud JA. Hepatic connective tissue changes in hepatosplenic schistosomiasis. Human Pathology 23: 566-573, 1992.

9. Arthur MJP. Matrix degradation in the liver. Seminars in Liver Diseases 10: 47-55, 1990 .

10. Arthur MJP. Reversibility of liver fibrosis and cirrhosis following treatment for hepatitis C (Editorial). Gastroenterology 122: 1525-1528, 2002.

11. Bedossa P, Paradis V. Liver extracellular matrix in health and disease. Journal of Pathology 200: 504-515, 2003.

12. Bhunchet E, Eishi Y, Wake K. Contribution of immune response to hepatic fibrosis by porcine serum. Hepatology 23: 811-817, 1996.

13. Bina JC. Influência da terapêutica específica na evolução da esquistossomose. Tese de Mestrado. Curso de Pós Graduação em Medicina Interna, Universidade Federal da Bahia, Salvador, BA, 1977.

14. Bina JC, Prata A. Regressão da hepatoesplenomegalia pelo tratamento específico da esquistossomose. Revista da Sociedade Brasileira de Medicina Tropical 16: 213-218, 1983.

15. Boros DL. Granulomatous inflammations. Progress in Allergy 24: 183-267, 1983.

16. Brown KE. An overview of hepatic fibrogenesis. Viral Hepatitis Reviews 6: $5-27,2000$
17. Cameron CR, Ganguly NC. An experimental study of the pathogenesis and reversibility of schistosomal hepatic fibrosis. Journal of Pathology and Bacteriology 87: 217-237, 1964.

18. Desmet VJ, Roskams T. Cirrhosis reversal: a duel between dogma and myth. Journal of Hepatology 40: 860-867, 2004.

19. Dietze RS, Prata A. Rate of reversion of hepatosplenic schistosomiasis after specific chemotherapy. Revista da Sociedade Brasileira de Medicina Tropical, 19: 69-73, 1986.

20. Di Vinicius I, Baptista AP, Barbosa Jr AA, Andrade ZA. Morphological signs of cirrhosis regression. (Experimental observations on carbontetrachloride-induced liver cirrhosis in rats). Pathology, Research and Practice, 2005.

21. Ferreira LA, Andrade ZA. Capillaria hepatica: a cause of septal fibrosis of the liver. Memórias do Instituto Oswaldo Cruz 88:441-447, 1993.

22. Friedman SL. Molecular regulation of hepatic fibrosis, an integrated cellular response to tissue injury. Journal of Biological Chemistry 275: 2247-2250, 2000

23. Friedman SL. Liver Fibrosis - From bench to bedside. Journal of Hepatology 38: 38-53, 2003.

24. Geerts A. History, heterogeneity, developmental biology, and functions of quiescent hepatic stellate cells. Seminars in Liver Diseases 21: 311-335, 2001.

25. Geert A, De Bleser P, Hautekeete ML, Niki T, Wisse E. Fat-storing (Ito) cell biology. In: Arias IM, Boyer JL, Fausto N, Jakoby WB, Schachter DA, Shafritz DA (eds) The liver: Biology and Pathobiology, $3^{\text {rd }}$ edition, Raven Press, New York, p. 819-838, 1994.

26. Gomez DE, De Lorenzo M, Alonso DF, Andrade ZA. Expression of collagenases (MMP1 and MMP9) and their inhibitors (TIMP1 and TIMP2) in schistosomal portal fibrosis. The American Journal of Tropical Medicine and Hygiene 61: 9-13, 1999.

27. Gonnert R. Schistosomiasis studien. IV. Zur Pathologie de Schistosomiasis der Maus. Zeitschrift fur Tropenmedizin und Parasitologie 6: 279-336, 1955.

28. Gross J. How tadpoles lose their tails: path to discovery of the first matrix metalloproteinase. Matrix Biology 23: 3-13, 2004.

29. Henell F, Bricsson JLE, Glaumann H. An electron microscopic study of the post partum involution of the rat uterus: with a note on apparent crinophagy of collagen. Virchows Archives B, Cell Pathology 42: 271-287, 1983.

30. Homeida MA, Ahmed S, Dafalla A, Sulliman S, Eltom I, Nash T, Bennett JL. Morbidity associated with Schistosoma mansoni infection as determined by ultrasound: a study in Gezira, Sudan. The American Journal of Tropical Medicine and Hygiene 39: 196-201, 1988.

31. Iredale JP, Benyon RC, Pickering J, McCullen M, Northrop M, Pawley S, Hovell C, Arthur MJP. Mechanisms of spontaneous resolution of rat liver fibrosis: hepatic stellate cell apoptosis and reduced hepatic expression of metalloproteinase inhibitors. Journal of Clinical Investigation 102: 538549, 1998.

32. Katz N, Brener Z. Evolução clínica de 112 casos de esquistossomose mansoni observados após dez anos de permanência em focos endêmicos de Minas Gerais. Revista do Instituto de Medicina Tropical de São Paulo 8: 139-142, 1966.

33. Lemos QT, Magalhães Santos IF, Andrade ZA. Immunological basis of septal fibrosis of the liver in Capillaria hepatica-infected rats. Brazilian Journal of Medical and Biological Research 36: 1201-1207, 2003.

34. Massarrat S, Fallahazad V, Kamalian N. Clinical, biochemical and imagingverified regression of hepatitis B-induced cirrhosis. Liver International 24: 105-109, 2004.

35. Mohamed-Ali Q, Doehring-Schwerdtfeger E, Abdel-Rahim IM, Schlake J, Kardoff R, Franke D, Kaiser C, Elsheikh M, Abdalla S, Schafer P, Ehrich $\mathrm{JHH}$. Ultrasonographic investigation of periportal fibrosis in children with Schistosoma mansoni infection: reversibility of morbidity seven months after treatment with praziquantel. The American Journal of Tropical Medicine and Hygiene 44: 444-451, 1991.

36. Okuno M, Moriwaki H, Smai S. Retinoids exacerbate rat liver fibrosis by inducing the activation of latent TGF-beta in liver stellate cells. Hepatology 26: 913-921, 1997. 
37. Paronetto F, Popper H. Chronic liver injury induced by immunologic reactions. Cirrhosis following immunization with heterologous sera. The American Journal of Pathology 40: 1087-1101, 1966.

38. Perez-Tamayo R. Collagen resorption in carrageenin granulomas. II. Ultrastructure of collagen resorption. Laboratory Investigation 22: 142157, 1970.

39. Perez-Tamayo R. Cirrhosis of the liver: a reversible disease? Pathology Annual 14: 183-213, 1979.

40. Perez-Tamayo R. Degradation of collagen: pathology. In: Weiss JB, Jayson MIV (eds) Collagen in Health and Disease. Churchill Livingstone, London, p. 135-159, 1982

41. Pinzani M, Marra F. Cytokine receptors and signaling in hepatic stellate cells. Seminars in Liver Diseases 21: 397-416, 2001.

42. Popper H. Pathologic aspects of cirrhosis. A Review. American Journal of Pathology 87: 227-264, 1977.

43. Poynard T, McHutchison J, Manns M, Trepo C, Lindsay K, Goodman Z, Ling $\mathrm{MH}$, Albrecht $\mathrm{J}$. Impact of pegylated interferon alfa-2b and ribavirin on liver fibrosis in patients with chronic hepatitis C. Gastroenterology 122: 1303-1313, 2002.

44. Quinn OS, Higginson J. Reversible and irreversible changes in experimental cirrhosis. American Journal of Pathology 47: 353- 369, 1965.

45. Ricard-Blum S, Ville G, Grimaud JA. Pyridinoline, a mature collagen crosslink, in fibrotic livers from Schistosoma mansoni-infected mice. The American Journal of Tropical Medicine and Hygiene 47: 816-820, 1992.

46. Richter J. The impact of chemotherapy on morbidity due to Schistosomiasis. Acta Tropica 86: 161-183, 2003.

47. Rose NR. Mechanisms of autoimmunity. Seminars on Liver Diseases 22: 387-394, 2002.
48. Rubin E, Hutterer F, Popper H. Experimental hepatic fibrosis without hepatocellular regeneration. American Journal of Pathology 52: 111-119, 1968.

49. Schinoni MI, Andrade ZA, Freitas LAR, Oliveira R, Paraná R. Incomplete septal cirrhosis: an enigmatic disease. Liver International, 24: 452-456, 2004.

50. Sciot R, Staessen D, Van Dame B, Van Steenbergen W, Fevery J, de Groote J, Desmet VJ. Incomplete septal cirrhosis: histopathological aspects. Histopathology 13:593-603, 1988.

51. Souza MM. Estudos sobre a fibrose septal hepática induzida por Capillaria hepática (Patogênese e Evolução) Tese de Doutorado, Universidade Federal da Bahia, Salvador, BA, 2003.

52. Souza MM, Paraná R, Trepo C, Barbosa Jr AA, Oliveira I, Andrade ZA. Effect of Interferon-a on Experimental Septal fibrosis of the liver -Study with a new model. Memórias do Instituto Oswaldo Cruz 96: 343-348, 2001

53. Souza MM, Silva LM, Barbosa Jr A, Oliveira IR, Paraná R, Andrade ZA. Hepatic capillariasis in rats: a new model for testing anti-fibrosis drugs. Brazilian Journal of Medical and Biological Research 33: 1329-1334, 2000.

54. Wanless IR, Nakashima E, Sherman M. Regression of human cirrhosis. Morphologic features and the genesis of incomplete septal cirrhosis. Archives of Pathology and Laboratory Medicine 124: 1599-1607, 2000.

55. Warren KS. The influence of treatment on the development and course of murine hepatosplenic schistosomiasis mansoni. Transactions of the Royal Society of Tropical Medicine and Hygiene 56: 510-519, 1962.

56. Warren KS. The pathogenesis of "clay-pipe stem cirrhosis" in mice with chronic schistosomiasis mansoni, with a note on the longevity of the schistosomes. The American Journal of Pathology 49: 477-489, 1966.

57. Warren KS, Klein L. Chronic murine hepatosplenic schistosomiasis mansoni: relative irreversibility after treatment. Transactions of the Royal Society of Tropical Medicine and Hygiene 63: 333-337, 1969. 